\title{
Resilience and Self Esteem of Adolescents from Government Schools in Mangaluru
}

\author{
Sphoorthi G. Prabhu' ${ }^{1}$, Rameela Shekhar ${ }^{2}$ \\ ${ }^{1}$ Research Scholar, Department of Social Work, School of Social Work, Roshini Nilaya, Mangaluru. \\ ${ }^{2}$ Dean, Post Graduate Department, School of Social Work, Roshini Nilaya, Mangaluru. \\ E-mail - sphoorthigprabhu@gmail.com
}

\begin{abstract}
Background: Adolescence is well known as a challenging phase. One of the determinants of adolescent mental health is the Socio-Economic Status (SES). Lower the SES, higher are the risks for mental health issues. However, resilience could avert this risk. Among many, Self-Esteem is one of the intrinsic factors for resilience. Understanding resilience and self-esteem of adolescents from Lower Socio-Economic Status (LSES) would enable professionals to design programs specifically for adolescents from LSES. With this background, this paper aims at discussing Resilience and Self-esteem in adolescents from Government schools in Mangaluru. The objectives are to understand the family background, SES and subjective adversities experienced by the adolescents, to assess their self-esteem and resilience and to know the correlation between the two.

Methodology: 580 adolescents (from grades $8^{\text {th }}$ to $10^{\text {th }}$ ) from 12 Government schools of Mangaluru Taluka of Karnataka State in South India formed the sample. CD-RISC 2 and Rosenberg's Self-esteem scales were the measurements used. Descriptive Statistics and Pearson's Correlation were used for analysis.

Results: The mean age of the adolescents was 13.42 years $( \pm 1.002)$. The Majority were from nuclear $(85.5 \%)$ and two parent families $(88.1 \%)$. The median family monthly income was `6000/-. The perceived economic status was also low and significant proportion have expressed of financial constraints and death in the family as adversities commonly experienced. They have moderate resilience and self-esteem and the two variables are positively correlated.

Conclusion: The study highlights the scope and need for mental health programmes in Government schools.
\end{abstract}

Key Words: Adolescents, Resilience, Self-esteem, Socio-Economic Status

(Paper received $-11^{\text {th }}$ December 2016, Peer review completed $-6^{\text {th }}$ January 2017, Accepted $-12^{\text {th }}$ January 2017)

\section{INTRODUCTION}

Different terminologies are in vogue to describe the adolescent stage, like the stage of 'crisis' and stage of 'storm and stress'. Although the phase related challenges are widely discussed, there is an increased need to emphasise on understanding and promotion of their strengths, especially considering the increased prevalence of mental health issues among adolescents. Understanding strengths enable the mental health professionals working with adolescents to go beyond assessment, diagnosis or labelling. This is specifically for adolescents from at-risk situations.

Among various risk situations, adolescents from poverty make up the majority which is associated with poor developmental outcomes [1] and mental health issues [2]. However, one's resilience could avert the negative outcomes. 
Resilience refers to bouncing back from a stress, risk or an adversity. The Policy from the World Health Organisation views resilience as something that embraces positive adaptation, with protective factors and assets that moderate risk factors and therefore reduce the impact of risk on outcomes [3]. Thus, there is a positive outcome despites risks. Various strengths or protective factors promote resilience. Self-esteem is one such intrinsic protective factor. Self-esteem refers to overall positive evaluation of oneself [4]. Positive self-concept and self image contribute to good self-esteem. The two dimensions of self-esteem are competence and worth [4] i.e. the degree to which people see themselves as capable and efficacious and as a person to be valued. Early childhood experiences, school experiences, type of parenting experiences, the extent of positive strokes enjoyed and one's temperament are some of the factors that influence one's selfesteem. The socio- economic status also has a role to play. The self-esteem of adolescents belonging to lower socio-economic status (LSES) is found to be lower [5] which could, in turn, affect one's resilience [6].

With this background, this paper aims at discussing Resilience and Self-esteem in adolescents from Government schools in Mangaluru. This paper is an outcome of an ongoing Doctoral study on the development of a culture specific scale to measure adolescent resilience that has received clearance from Institutional Ethical Review Committee. As a part of the Doctoral study, the self-esteem and resilience were measured. The study included adolescents from different backgrounds which also included adolescents from Government schools. It is observed that majority of the children and adolescents from LSES enrol in Government schools considering the free education and free provision of other requirements like books. Understanding their self-esteem and resilience, as intended by the current paper, has its implications in designing mental health programmes for students from Government schools and would reflect the scope for the same. Therefore, the objectives of the paper are to understand the family background, SES and subjective adversities experienced by the adolescents, to assess their self-esteem and resilience and to find out the correlation between self-esteem and resilience.

\section{METHODOLOGY}

Cross sectional descriptive research design was used. The school going adolescents of Mangaluru city were the target population. The study population was adolescents from grades $8^{\text {th }}$ to $10^{\text {th }}$ of Government schools. As mentioned earlier, for the Doctoral study 800 adolescents from different schools formed the sample. The selection of the schools was primarily based on proximity and permission received from the Headmaster/ Headmistress. The selection of students was based on the parental consent and student assent received. For the purpose of this paper, only adolescents from Government schools were considered. Thus, students from 12 Government schools from Mangaluru formed the study population. A total of 580 students from these 12 Government schools formed the sample.

\section{Measurements -}

The variables resilience and self-esteem were measured using the following standardized scales.

a. CD-RISC 2: The CD-RISC 2 is an adaptation of the original 25 items Connor Davidson Resilience Scale by Vaishnavi, Connor, Davidson [7]. It consists of items 1 and 8 of the original scale. This, 2 items version, was developed as a measure of bouncing back. It is considered to be a reliable and valid tool. The CD- RISC 25 is validated for the Indian Population [8]. Higher scores indicate high resilience. The maximum score is 8 .

b. Rosenberg Self-esteem Scale: Developed by Rosenberg [9] is 10 items, 4 point likert scale. A highly valid and reliable tool is widely used in Indian context [10] and with adolescent population scores between 15 and 25 suggests self-esteem to be in normal range and scores below 15 suggest low self-esteem. The lowest score is 0 and highest is 30 .

c. A socio-demographic sheet prepared by the researcher was used to know the socio-demographic background of the respondents. This also consisted of a checklist of various adverse situations (commonly associated with LSES families) experienced for the past 1 year. They had to indicate those adversities that were experienced by them. Apart from these, they had to also write any other adversity experienced by them. 
Apart from the socio-demographic tool, the other two scales were in English. Therefore, the items were read and explained to the students in group to ensure reliable responses. The data collection was between June 2016 to October 2016.

\section{STATISTICAL ANALYSIS}

The data was analysed using the SPSS 19 version. Descriptive statistics and correlations were used.

\section{RESULTS}

Table 1: Socio- Demographic Details of the Respondents

\begin{tabular}{|ll|}
\hline Variable & Percentage \\
\hline Gender & \\
Male & 52.8 \\
Female & 47.2 \\
\hline Grade (Class) & \\
8th & 35.7 \\
9th & 53.8 \\
10th & 10.5 \\
\hline Mean Age: $13.42( \pm 1.002)$ \\
\hline
\end{tabular}

As represented in Table 1, majority of the respondents were boys (52.8\%) and from class $9(53.8 \%)$. There was a minimal representation of class 10 students due to the denial of their participation by the School Authority considering their packed up academic schedule as a preparation for the board examinations. The sample was representative of mid- adolescence phase indicated by the mean age of 13.42 years ( \pm 1.002). Although age is one of the criteria for the admission and promotion of students to a particular class/ grade, this was not seen with regard to some students. Drop outs and re-admission was one of the reasons for this.

Table 2: Family Background of the Respondents

\begin{tabular}{|ll|} 
Variable & Percentage \\
\hline Family Type & \\
\hline Nuclear & 85.5 \\
\hline Joint & 11.9 \\
\hline Staying With Extended Relatives & 1.0 \\
\hline Staying in Institution & .3 \\
\hline No mention made & 1.2 \\
\hline Presence of Parents & \\
\hline Father as a single parent & 1.7 \\
\hline Mother as a single parent & 9.3 \\
\hline Both parents present & 88.1 \\
\hline Both parents absent & .5 \\
\hline No mention made & .3 \\
\hline
\end{tabular}

With regards to the family background, as indicated in table 2, majority (85.5\%) of the respondents were from nuclear families. A very small proportion (1\%) of the respondents were away from home for education, hence were staying with their extended relatives. Likewise, the $0.3 \%$ who live in institutions were the ones with no families. As far as parental status is concerned, the majority $(88.1 \%)$ were from two 
parent families. While a few had only single parents (11\%), $0.5 \%$ were ones whose parents had deceased and were supported by extended relatives.

Table 3: Socio- Economic Status of the Parents

\begin{tabular}{|ll|}
\hline Father's Qualification & Percentage \\
\hline Uneducated & 6.5 \\
\hline Primary & 22.8 \\
\hline Higher Primary & 40.3 \\
\hline Secondary & 16.6 \\
\hline Higher Secondary & 9.8 \\
\hline UG & .7 \\
\hline Do Not Know & 1.5 \\
\hline Mother's Qualification & \\
\hline Uneducated & 16.8 \\
\hline Primary & 29.5 \\
\hline Higher Primary & 38.3 \\
\hline Secondary & 10.2 \\
\hline Higher Secondary & .9 \\
\hline UG & .3 \\
\hline Not Applicable & 1.9 \\
\hline $\begin{array}{l}\text { Do Not Know } \\
\text { Median of Family }\end{array}$ & 1.7 \\
$\begin{array}{l}\text { `6000.00 } \\
\text { Minimum: `0 } \\
\text { Maximum: `60,000 }\end{array}$ \\
\hline
\end{tabular}

Table 3 shows majority of the respondents' parents being qualified only till higher secondary, which was either $11^{\text {th }}$ or $12^{\text {th }}$ grade, points to the low parental qualification. The LSES of these families were indicated by the median of ' 6000 . Most of the families had fathers as the sole earning member who were involved in unorganized work which fetched daily/ weekly wages. Though very few, there were families that had no income and were supported by relatives. On the other hand, in some other families the earning member(s) were self- employed or involved in labour with good wages due to which their family monthly income was relatively better.

Figure 1-Adversities Experienced by the Adolescents

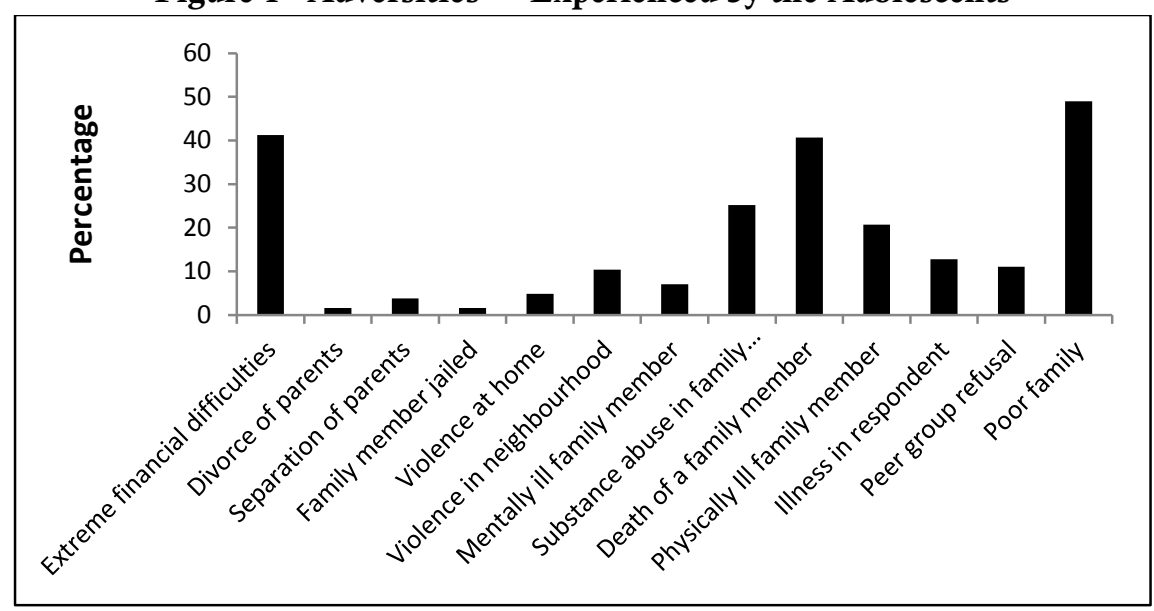

Apart from the poor economic status, as indicated in Table 2, the other adversities experienced for the past one year by these adolescents are highlighted by Figure 1. It was observed that, the adversities reported to 
be experienced by a significant proportion of the sample were financial difficulties (41.2\%) and death of a family member with whom they were intimate (40.7\%). Most importantly, a significant proportion of the sample (49\%), perceived that they belonged to a poor family and thus, considered it as an adversity. Apart from their responses to the checklist, the majority of the respondents did not subjectively express any additional adversities. Of those who have, the emphasis was again on financial issues and conflicts between family members. Overall, the presence of objectively evident associated adversities has been minimal.

Table 4 - Mean Scores of Self-esteem and Resilience

\begin{tabular}{|lll|}
\hline & Resilience & Self-esteem \\
\hline Mean & 4.5207 & 19.9227 \\
$\begin{array}{l}\text { Standard } \\
\text { Deviation }\end{array}$ & 1.77332 & 3.45458 \\
\hline
\end{tabular}

In spite of the adversities expressed, the Self-esteem and Resilience scores are average as seen in Table 4. For both the variables, higher scores indicate better Self-esteem and Resilience. The scores of the sample are neither high nor low indicating the normal scores on both the variables.

Table 5: Correlation between Resilience and Self-esteem

\begin{tabular}{|llll|}
\hline & & Self-Esteem & Resilience \\
& Pearson Correlation & 1 & $.212^{* *}$ \\
& Sig. (2-tailed) & & .000 \\
Resteem & $\mathrm{N}$ & 569 & 569 \\
& Pearson Correlation & $.212^{* *}$ & 1 \\
& Sig. (2-tailed) & .000 & \\
& $\mathrm{~N}$ & 569 & 580 \\
$* *$. Correlation is significant at the 0.01 level (2-tailed). & \\
\hline
\end{tabular}

Positive, but weak correlation between Self-esteem and Resilience is reflected in Table 5. The significant value of .000 is indicative of the same. This points out to the significance of self-esteem in the resilience of an adolescent.

\section{DISCUSSION}

In India, children and adolescents from LSES are usually enrolled in Government schools. The basic schooling requirements of children are fulfilled by these schools to ensure the continuity of schooling by the students. A common problem experienced by these students is the financial constraints and the associated issues; which is also corroborated through this study.

The sample's representation of adolescents from LSES was indicated through the median family monthly income of ' $6000 /$ - where the parents commonly involved in the unorganized occupation. This becomes important while discussing the health and mental health of adolescents. Generally, the socio-economic status of an individual is one of the important determinants of health and mental health. Literature suggests that individuals from LSES are at an increased risk to develop psychiatric disorders considering their inability to possess and consume goods that are valued in society [11] and stress as a primary psychological pathway linking LSES to poor health. This is significant in children and adolescents from the socio-economically disadvantaged group. They are two to three times more likely to develop mental health issue. Longer the persistence of the LSES, higher was the rate of mental health problems [2]. Exposure to the risks associated with LSES has a vital role to play. Moreover, the subjective report of low 
socio-economic status, also seen in the current study, is found to be associated with physical symptoms and psychological distress [12]. Thus, the risk for mental health issues is doubled.

Intense stress related to financial constraints and the unhealthy family environment, poor resources could decrease the competencies in an adolescent. For instance, the poor parental education, also seen in this study, is suggested to be contributing to the development of pessimistic views of one's future [11] which is unhealthy. Likewise, the lack of materialistic possessions could hinder the identity development as the same is considered to have a significant role in creating, maintaining and preserving one's identity [13]. As shown by this study, in addition to financial constraints experienced, a significant proportion of the adolescents had revealed the presence of other issues like the death of a family member with whom they were closely related. This throws light on the fact that adolescents from LSES experience other related adversities, apart from financial constraints, which is a significant risk. Crowded neighbourhoods, poor access to care due to the absence of economic resources and unhealthy behaviours like substance intake increase the morbidity and mortality [14] which can be attributed to death in the families of the respondents of this study.

Although the adolescents were from LSES and were experiencing a few associated risk factors, they did emerge as resilient. Various protective factors- assets (intrinsic) and resources (extrinsic)-contribute to resilience despites risk. Some of the resources include parental support, adult mentoring, support from teachers, adults in the community, community organizations etc. The absence of significant adversities associated with LSES in majority of the respondents' families is suggestive of presence of family as a resource. Among various assets like competence, coping skills; self-esteem is also a significant one [1]. This study affirms positive self-esteem in adolescents from LSES. As indicated by an early theory [15], one's worth is learnt through comparison with others and others attitude towards self. More often, the comparison would be with those in the immediate environment- school and community where SES would be same as his/her without significant difference. Secondly, the adolescent would view himself through the eyes of others who would generally be the significant others whose opinion would most often be positive. These social representations and psychological interpretations contribute to self-esteem development. Therefore, adolescents from LSES can have positive self-esteem which further contributes to resilience. This relation between resilience and self-esteem is also established by the current study i.e. higher the selfesteem, higher would be the resilience. However, the weak relation suggests the possible significant role of other factors for adolescent resilience.

Although this study showed minimal adversities experienced by adolescents from LSES in Mangaluru, the possibility of under reporting due to social desirability cannot be disregarded. Likewise, though the adolescents displayed positive self-esteem and resilience, the average scores imply the scope for further enhancement of the same. This is proposed bearing in mind the fact that individuals at high risk who are resilient at one point of time, may not be so in another and long term consistent positive adjustment may not be seen [16]. This transient nature of resilience cannot be ignored. Nevertheless, the possible decline in adolescent resilience in the context of increased adversities could be averted through a continuous attempt in facilitation and maintenance of the determinants of resilience.

\section{CONCLUSIONS}

Globally, there is an increased emphasis on the programmes for prevention of mental health issues that applies to the child and adolescent population as well. However, in India, the need for child or adolescent mental health programmes are stressed by some of the existing policies such as National Health Policy, Integrated Child Development Scheme and National Mental Health Program [17]. In Mangaluru, some of the private schools have these programmes as a part of their curricular schedule. In majority of the schools though the school mental health programmes are conducted, the same is infrequent, for short term duration and is consequently ineffective. The frequency of these programmes is lower in Government Schools due to various reasons.

On account of the findings of the current study, it may be proposed that there is a need for frequent promotional programmes in Government Schools of Mangaluru under the purview of the existing policies. 
Promotional programmes that focus on the promotion of determinants of resilience would ensure healthy development of the adolescent despites some of the risks associated to LSES.

\section{REFERENCES}

1. Fergus S, Zimmerman A. Adolescent Resilience: A framework for understanding healthy development in the face of risk. Ann Rev Pub Health 2005;26:399-419.

2. Reiss F. Socio-economic inequalities and mental health problems in children and adolescents: A systematic review. Soc Sci Med 2013;90:24-31.

3. Windle G, Bennett KM, Noyes J. A methodological review of resilience measurement scales. Health Qual Life Outcomes 2011;9(8):1-18.

4. Joshi S, Srivastava R. Self-esteem and academic achievement of adolescents. J Indian Acad Appl Psychol 2009;35:33-9.

5. Veselska Z, Geckova MA, Gajdosova B, Orosova O, Dijk VJP, Reijneveld SA. Socio-economic differences in self-esteem of adolescents influenced by personality, mental health and social support. Eur J Pub Health 2010;20(6):647-52

6. Ryan L, Caltabiano ML. Development of new resilience scale: The resilience in midlife scale. Asian Soc Sci 2009;5(11):39-51.

7. Vaishnavi S, Connor K, Davidson JRT. An abbreviated version of the Connor-Davidson Resilience Scale (CD-RISC), the CD-RISC2: Psychometric properties and applications in psychopharmacological trial. Psychiatry Res 2007;152(2-3):293-7.

8. Singh K, Yu X. Psychometric Evaluation of the Connor-Davidson Resilience Scale (CD-RISC) in a Sample of Indian Students. J Psychology 2010;1(1):23-30.

9. Hagborg WJ. The Rosenberg Self-Esteem scale and Harter's Self-Perception profile for adolescents: a concurrent validity study. Psychol Schools 1993;30(2):132-6.

10. Srikala B, Kumar K. Empowering adolescents with life skills education in schools- School mental health program: Does it work?. Indian J Psychiatry 2010;52(4):344-9.

11. Stepleman LM, Wright DE, Bottonari KA. Socioeconomic status: Risk and resilience. In: Loue S, Sajatovic M, editors. Determinants of Minority Mental Health and Wellness. Springer, 2008. pp 297-302.

12. Sweeting $\mathrm{H}$, Hunt $\mathrm{K}$. Adolescent socio economic and school based social status, health and well being. Soc Sci Med 2014;121:39-47.

13. Gentry J, Baker MS, Kraft BF. The role of possession in creating, maintaining and preserving one's identity: Variation over the life course. Adv Consumer Res 1995;22:413-8.

14. Chen E, Strunk RC, Trethewey A, Schreier HMC, Maharaj N, Miller GE. Resilience in low socioeconomic status children with asthama: Adaptations to stress. J Allergy Clin Immunol 2011;128 (5): 970-6.

15. Rosenberg M, Pearlin LI. Social Class and Self-Esteem Among Children and Adults. Am J Sociology 1978; 84(1):53-77.

16. Luthar SS, Cichetti D, Becker B. The construct of resilience: A critical evaluation and guidelines for future work. Child Dev 2000;71(3):543-62.

17. Vranda MN. Promotion of mental health and well being of adolescents in schools- A NIMHAANS model. J Psychiatry 2015;18(5):2-5.

$$
\begin{aligned}
& \text { Acknowledgements - Nil } \\
& \text { Source of Funding - Nil } \\
& \text { Conflict of Interest - Nil }
\end{aligned}
$$

